\title{
Ergo 0
}

Erratum: The original published version of this paper incorrectly attributed, in $\$ 5$, an unpublished manuscript to Alan Soble. That manuscript is by an anonymous author who is not Alan Soble. The author regrets the error, and apologizes to Professor Soble for the misattribution. (The references to Soble (I987) are accurate.)

\section{Modal Monogamy}

\section{C.S.I. JENKINS}

\section{University of British Columbia}

Patience: Why, how could I love him and love you too? You can't love two people at once!

Bunthorne: [Aside.] Oh, can't you, though! [Aloud.] I don't believe you know what love is!

Patience: [Sighing.] Yes, I do. There was a happy time when I didn't, but a bitter experience has taught me.

\section{Introduction}

To begin, I want to distinguish two hypotheses:

Moral Monogamy: The only morally permissible romantic love relationships are monogamous ones.

Modal Monogamy: The only metaphysically possible romantic love relationships are monogamous ones.

For the purposes of this paper I am focusing on Modal Monogamy. (I will give a precise definition of "monogamous" in section 2 below.)

Modal Monogamy appears to operate as an unargued assumption in many philosophical discussions of romantic love. Often, Modal Monogamy (or some claim that entails it) is treated as being so obvious as to require no defence or even comment. Sometimes it is even treated as (partly) definitive of romantic love.

To give just a few examples, Robert Solomon (I988: 197) tells us that "[l]ove is the concentration and the intensive focus of mutual definition on a single individual, subjecting virtually every personal aspect of one's self to this process". Matthew Liao (2006: I6) says that "[w]e should love another person romantically because we want to and not because we have to, especially since loving someone romantically requires exclusive focus on the person". Alan Soble (I987:389) says "exclusivity ... is actually an essential part of romantic love", making explicit 
elsewhere in his paper that he means exclusivity between exactly two people, and even that this claim forms part of a conceptual analysis of romantic love. And so on. (All emphases in this paragraph are added.) ${ }^{\mathrm{T}}$

This trend is by no means limited to philosophy. To get some sense of the range of this kind of assumption, consider that sociologist Eva Illouz (20I 2:I 8) writes: "to love is to single out one person among other possibilities", and anthropologist Helen Fisher (in her 2008 TED talk "The Brain In Love") says that:

... romantic love is a drive, a basic mating drive. Not the sex drive; the sex drive gets you out there looking for a whole range of partners. Romantic love enables you to focus your mating energy on just one at a time, conserve your mating energy, and start the mating process with a single individual.

And Modal Monogamy and related assumptions even more commonly fly under the radar, both in philosophy and elsewhere. There exist a large number of philosophical papers and books on the nature of love which include no explicit statement flagging the assumption but proceed as if none were even needed. These discussions routinely includes unremarked use of phrases like "the couple", "the other person", and so on, and employ examples, thought experiments etc. that pertain to monogamous love relationships only.

If an example is needed, one might look at Kisolo-Ssonko (20I2). This short paper discusses many thought-experimental cases of romantic love, including same-sex cases, but they are all about couples (and this fact is not remarked upon).

I. There are exceptions. Some philosophers do consider the possibility of non-monogamous love. However, it is noticeable that they tend to follow up by reinforcing monogamy as natural, normal, or important. Chapter 7 of Jollimore (20II), for example, includes a careful discussion of whether romantic love should ideally be monogamous, and ultimately does not attempt to settle this question. However, he includes a comment about what is "natural" for "people":

It seems highly likely that, at least in our own society and others like it, most people will continue to regard some degree of sexual exclusivity as a central element of romantic love. People are naturally inclined to feel this way [...]. (I63, emphasis added)

Likewise, Caraway (I987) allows that non-exclusive love is possible, though she follows this up with a claim about the importance of exclusivity: "exclusivity is important to romantic love because it promotes intimacy and psychological union" (4II).

There are also significant variations in how deeply embedded the assumption of romantic monogamy is for different authors; in Soble (I987), for example, it is a central part of a conceptual analysis, whereas for Liao it is only assumed at some points, while other statements are more circumspect. For example, Liao says that "at least in the case of romantic love, an exclusive focus on a particular person may [emphases added] be required" (2006: II).

There are also many extant philosophical discussions of marriage and/or sex that do not assume (and in several cases explicitly question) exclusivity and/or dyadicity in these domains. One excellent example is Weaver and Woollard (2008). However, as mentioned above, my focus here is on romantic love, for which neither sex nor marriage can stand proxy. 
The discussion also repeatedly moves from talking about romantic unities or collectives to talking about romantic couples, and vice versa, again without remarking the shift. Kisolo-Ssonko also, notably, treats attraction to others outside the couple as one of the distinguishing features of a thought-experimental case that he labels coming apart (2OI 2: 60). This suggests that the couples of Kisolo-Ssonko's thought-experiments are all assumed without comment to be monogamous couples. (I mention Kisolo-Ssonko (20I2) not because it is in any way unusual, but only because it happens to be recent, and it is among my concerns here to demonstrate that the assumption of romantic monogamy has wide contemporary sway.)

A certain amount of this sort of thing might be done without assuming anything as strong as Modal Monogamy, of course. But when it is done persistently enough, it becomes clear that a methodological presumption has been made no other kinds of love could be relevant to a philosophical investigation of what love is. Such a presumption is appropriate if Modal Monogamy is so obvious as to need no comment. It is otherwise questionable, on fairly obvious methodological grounds: conclusions based on consideration of only a favoured subset of cases of a phenomenon may not be sufficiently general to deliver a promising account of what the phenomenon is.

Some of the implications of this sort of general methodological point are (if gradually) being implemented in contemporary philosophical discussions of love. For example, it is now much more common than it was (say) twenty years ago to see clear inclusion of non-heteroromantic love in philosophical discussions. This may take the form of simply including same-sex couples among the thought experiments, as in e.g., Kisolo-Ssanko (2012), or making explicit inclusive remarks in the style of e.g., Westlund (2005). (See footnotes 5 and 8, where it is simply stated outright that the account is not restricted to heterosexual love alone.)

In effect, the philosophy of love (or at least its more progressive segment) has managed to get back to being approximately as inclusive as the Aristophanes myth of Plato's Symposium was two thousand years ago, which likewise explicitly aimed to account for both heteroromantic and homoromantic love. And as per the Aristophanes myth, contemporary philosophers of love generally assume that romantic love is monogamous. (The creatures of the myth are each divided into two beings, who then must find each other and nobody else.) While there are a few extant philosophical discussions of love where non-monogamy is explicitly raised as an issue for debate (typically followed up with reassurances about the favoured status of monogamy), there are to my knowledge none where the straightforward kinds of inclusion described in the previous paragraph are extended to cases of non-monogamous love.

In defence of the continued exclusion of non-monogamous love, it might perhaps be argued that such love is uncommon or unusual. However, firstly, any such claim would be on a very poor epistemic footing. There is no reliable informa- 
tion concerning even the numbers of people practising serious non-monogamous loving relationships (owing partly to the fact that the vast majority of those in such relationships experience considerable social pressure to keep this fact secret). ${ }^{2}$ There is even less rigorous information on how many people actually experience non-monogamous romantic love. However, the theme of feeling torn because a choice is required between two people both of whom one loves is hardly a rarity in popular music, classic literature, advice columns, and other art forms. It is important to be clear that Modal Monogamy can be falsified not only by polyamorous relationships but also by many other situations that would currently be regarded as more "normal". 3

Secondly, the rarity defence is not relevant to metaphysicians seeking to understand the phenomenon of love in general (rather than, say, looking to theorise solely about its most common or socially acceptable forms). Metaphysics, as a rule, does not shy away from considering unusual cases. If anything, it might actively seek them out: after all, cases that strike one as unusual can often be a good place to look for lessons one hasn't learned yet; the more usual-seeming cases will typically already have informed philosophical theorising to a much larger extent.

There are various grades of modality weaker than metaphysical modality; correspondingly, weaker variants of Modal Monogamy can be formulated. Some of these variants can also be found as operative assumptions in the philosophical literature. Robert Nozick, for example, states that "it is not feasible for a person to simultaneously to be part of multiple romantic couples (or a trio), even were the person to desire this" (I989: 84). This looks like a weaker modal claim about what is possible within the bounds of feasibility. A different weaker modal claim is made by Raja Halwani, who says that it is "generally necessary [emphasis added]" (and a "crucial feature of romantic love") that it be exclusive. He says the same of the requirement that (when reciprocated) love "exists between only two people" (2010: 27).

Interesting and debatable though such weaker modal claims are, ${ }^{4}$ in this paper

2. For comparable points specific to the US context, see Elizabeth Sheff's blog post, "How Many Polyamorists Are There in the US?", http://www.psychologytoday.com/blog/the-polyamorists-nextdoor/201405/how-many-polyamorists-are-there-in-the-us

3. Thanks to Paul Prescott for helping me to appreciate the significance of this point.

4. What is "feasible", for example, is very often a product of one's social situation. It might be imagined that multiple love relationships would take up far more time and energy and resources than just one, and so are not feasible, or only feasible for people with a lot of time and money on their hands. However, non-monogamous relationship structures can in some cases provide a way for people who are struggling for resources to pool incomes, share childcare responsibilities, and so on (as with other kinds of extended family or communal living). There is also an epistemological point worth making here: the impression that non-monogamy is "for" rich people with time on their hands may be at least partly a product of the fact that the consequences of openly engaging in a stigmatized type of relationship are fewer, and less devastating, for those buffered by other forms of privilege such as wealth. 
I will focus on the claim that non-monogamous love is metaphysically impossible, leaving variants containing other modalities for another occasion. I will just make two brief points about them here. First, guided by principles of interpretative charity, ${ }^{5}$ I would hypothesise that some philosophers who appear to be assuming or committing themselves to something like Modal Monogamy might really have some weaker claim, such as Nozick's feasibility claim, in mind (or at least might be prepared to retreat to such a weaker claim if pressed). Second, however, it is important to be clear that these weaker claims do not straightforwardly avoid the problems faced by Modal Monogamy. For example, the adoption of one of these weaker claims in the context of a philosophical investigation of what love is may well tend (intentionally or otherwise) to direct philosophical attention onto a limited subset of cases of love, and it is probable that these will be, or include, the usual-seeming cases that have plausibly already been very influential in informing philosophical theorising. That is to say, the same kinds of methodological risks faced by those who assume Modal Monogamy can also plague those who assume these weaker variants. ${ }^{6}$

It also strikes me as a somewhat viable (though perhaps less charitable) interpretative hypothesis that for at least some of those who assume Modal Monogamy, Moral Monogamy is tacitly motivating, or even perhaps even being conflated with, its modal counterpart. (Utterances like Patience's "You can't love two people at once!" admit of both moral and modal readings.) But I take it to be obvious, at least once the two theses are laid out side by side, that they are distinct and there is no straightforward way to infer from the latter to the former. ${ }^{7}$

I also take it to be obvious that any account of love which cannot accommodate the possibility of states of affairs which are in fact possible is thereby a mistaken account, regardless of the moral standing of such states of affairs. For my current purposes, therefore, the truth-value of Moral Monogamy is largely irrelevant: even if it is true ${ }^{8}$ Moral Monogamy is both distinct from, and insufficient to motivate, Modal Monogamy. (Compare: an account of killing which made murder metaphysically impossible would be a mistaken account of killing, regardless of whether or not murder is morally wrong. ${ }^{9}$ )

5. I am indebted to Colin Klein and an anonymous referee here.

6. That said, I would consider this paper to have achieved one of its principal aims even if all it serves to do is encourage greater clarity around what sorts of modality are intended when philosophers make claims that sound like assertions of Modal Monogamy and/or appear to entail Modal Monogamy.

7. It is more plausible that there could be an interesting inference in the other direction: from Modal Monogamy to Moral Monogamy. However, as I hope will become clear over the course of this paper, that would be an inference with a false premise.

8. It is not.

9. It is. 


\section{Some Definitions, Some Clarifications, and Some Arguments}

I use "love" in this paper to refer to romantic love. ${ }^{10}$ I use "love relationship" to describe the relationship that holds between a lover and the object(s) of the lover's love. It is not necessary for the obtaining of a love relationship in this sense that it be publicly acknowledged by its participants, formalised, socially recognised, etc. I also do not assume that love must be reciprocated in order to be genuine. More generally, I do not assume that a "love relationship" in my sense will always be the kind of thing we would normally expect to hear described as "a relationship" in the romantic sense. Love will also not be assumed to have any particular connections to sex or to marriage. ${ }^{\text {II I }}$ shall not attempt any definition or substantive theory of love in this paper (although I do have some things to say about some existing views).

I'll use "dyadic" to describe love relationships that involve exactly two parties. And I'll use "exclusive" to describe love relationships which are such that the lover in them is the lover in no further love relationships borne towards anyone not involved in the original love relationship. These terminological choices are perforce somewhat stipulative; this is required for clarity and precision in an area where vagueness and ambiguity are pervasive. The terms I'm employing are commonly used with a variety of different, and imprecise, meanings. ${ }^{\mathrm{I2}}$

An initial clarificatory point to note is that dyadicity and exclusivity as I have characterised them are not the same thing. They are in fact two-way independent. An example of an exclusive but non-dyadic love relationship is that which holds between lover and beloveds in a closed triadic relationship. A closed triad is a relationship in which three people are all in (mutual) love, but none of them is in love with anyone else. An example of a dyadic but non-exclusive love relationship is that between hinge lover and beloved in one of the two love relationships which comprise a $V$. A V is a relationships situation in which one person is in two (distinct) love relationships with two other parties (who are not in love with each other). The hinge of the $\mathrm{V}$ is the person who is party to both relationships.

Note that I am using this terminology in such a way that in the case of a closed triad the lover bears a single love relationship to her two beloveds jointly, whereas in the case of $\mathrm{V}$ the hinge lover bears two distinct love relationships to her two

Io. As I think it is plausible that romantic love is at least in part socially constructed (more on this in section 5 below), it is worth noting that I am talking about romantic love as it exists in the context of contemporary Western Europe, the US and Canada, and other places to which these are sufficiently culturally similar.

II. For this reason, many extant philosophical discussions of sexual and/or marital exclusivity do not bear directly or obviously on the topic under discussion here (important and interesting though they are in their own right).

I2. For example, on some uses, an "exclusive" love relationship must be a sexually exclusive one.

Ergo $\cdot$ vol. 2, no. 8 2015 
beloveds severally. (It is consistent with this, however, that the lover in the closed triad also bears distinct love relationships to each of her two lovers severally. ${ }^{\mathrm{I}}$ )

It is also perhaps worth noting explicitly that as I use "dyadic" and "exclusive", both are wholly descriptive terms (i.e., free of normative content).

For all I have said so far, it may be that such love relationships as are described in the triad and V situations are metaphysically impossible. But for my definitional purposes here, all that matters is that coherent descriptions of them can be given which make clear the intended difference between dyadicity and exclusivity.

I will use "monogamous" here to describe love relationships which are both dyadic and exclusive. Again, this is of necessity a somewhat stipulative definition.

Despite being so often taken for granted, or even treated as a matter of definition, there is reason to believe Modal Monogamy is in fact false. In fact, there are a number of reasons think so. I will state three here, in descending order of compellingness.

First, there exist many actual (and hence possible) people who take themselves to be in non-monogamous love relationships. Unless all such people are either confused or lying, Modal Monogamy is false. And I know of no reason to suppose that all such people are either confused or lying.

Second, analogies with other kinds of love suggest that non-dyadic and nonexclusive romantic love is possible. For example, it is possible to have multiple dyadic loving but non-romantic friendships, or a triadic loving but non-romantic friendship. Similarly, it is possible to love multiple children, multiple parents, etc. Some might want to respond here that romantic love is to be distinguished from these other kinds of love partly in virtue of the former's being necessarily limited to the exclusive dyadic case. But this response assumes Modal Monogamy; if employed as a way to resist the argument from analogy, it would be patently question-begging.

Third, Modal Monogamy is a very strong claim. It can be construed as having the form of a double universal quantification: all possible worlds are such that all the love relationships they contain are monogamous. Correspondingly, its negation is a weak, doubly existential, claim: at least one possible world has at least one non-monogamous love relationship in it. Thus it is reasonable to treat the negation as rather plausible by default, and Modal Monogamy as in need of substantial argument if it is to be accepted.

I am not sure what kind of argument could be mounted in favour of Modal Monogamy except one based on the claim that it is intuitive, true by definition, and/or a conceptual truth (or something in that ballpark). I shall return to such considerations in section 5 below.

I3. For the curious, this is why I elected to define exclusive love relationships as those which are such that the lover in them is the lover in no further love relationships borne towards anyone not involved in the original love relationship, rather than simply requiring that the lover in them be the lover in no further love relationships tout court. 
Assuming, for the time being, that Modal Monogamy is indeed false, it follows that theories of love which require the truth of Modal Monogamy must be either amended or rejected. In the next two sections, I will discuss one theory for which the needed amendment seems readily available (section 3), and another for which more careful thought seems to be required to develop such an amendment (section 4).

These two theories are chosen primarily because they have both been defended in print very recently. Modal Monogamy is not an outdated assumption that is no longer operative or worthy of attention. It does central work in contemporary philosophical theorising about love.

\section{3. "A Textbook Example of a Non-Symmetric Dyadic Relation"}

Thomas Smith, in the introductory remarks to his (20I I), writes: "[r]omantic love, as I understand it, is the form of love appropriate to all and only couples" (68). As I read him he is only attempting to fix reference in this passage; he develops a substantive theory of romantic love in the remainder of paper. But note that this reference-fixing move entails that non-dyadic romantic love is "inappropriate", which appears to be a version of Moral Monogamy (or perhaps some non-moral normative cousin thereof).

Smith makes no particular acknowledgement of, or argument for, the assumption that only dyadic love is "appropriate". He also does not say explicitly whether non-exclusive love is also supposed to be inappropriate or not, but Smith writes against a cultural background in which the assumption of exclusivity in dyadic romantic relationships is the norm. He does not define "couple" but invites us to draw on a pre-theoretic sense of what is meant. So I assume that he intends us to embed the culturally standard assumptions (since he would presumably otherwise guard against them explicitly). Hence it seems likely that he just does not find it necessary to mention that "couples" as he envisages them are exclusive couples.

What I want to draw attention to in this section is that when we turn to Smith's substantive theory, what starts out as a normative assumption, used to fix reference, appears to get inflated into a modal constraint on what can count as romantic love. Here is Smith's presentation of his substantive view of what love is:

Each lover participates, with the other, in doing things of the mentioned sorts out of Frankfurtian love: his love for the activities, which, in turn, is expressive of his love for the plurality of agents of them. The latter love has the four features Frankfurt lists, it is disinterested, rigidly focussed, identifying and involuntary. But it has, as its object, a plurality of people, oneself and one's partner. 
The hypothesis accommodates Frankfurt's view almost completely. He is quite right about the nature of love, according to the hypothesis. It is just that he overlooks the possibility that love may have a plural object. In particular, he overlooks the possibility that each one of two lovers may love, not just the other but the two of them, collectively. Such love, I hypothesise, is distinctive of romantic love, it finds expression in doing things, of the sort described, with one's beloved, things valued for themselves, simply because they are expressive of such love for a plurality.

The hypothesis also accommodates Nozick's account in the following way. Whilst he is right to say that lovers want to form and sustain a we, what he neglects to observe is that something distinctive of romantic love is that the desire in question is no mere desire; it is Frankfurtian loving concern, which is, unlike the desires to form wes had by business or creative partners, both a disinterested, and an involuntary one. (20II: 79-80)

Noteworthy here is the fact that Smith takes it to be a requirement on romantic love that it involve an attitude towards "a plurality of people" that contains exactly two members, namely "oneself and one's partner".

We might now wonder whether romantic love as Smith understands it (Smithlove, for short) is truly dyadic in my sense. Does Smith-love "involve exactly two parties", in line with my definition of dyadicity above, or is there now also a third party in the picture, namely the plurality of the two partners?

Let me clarify (again somewhat stipulatively) that Smith-love should count as "dyadic" in my intended sense. To get this result I'll stipulate that the "parties" to a Smith-love relationship do not include the plurality, but only the original parties (the two members of the couple). This enables me to talk about the parties to a Smith-love relationship as distinct from the subject and object of that relationship. (The object, according to Smith, is the plurality, which in my terminology is not one of the parties.) The advantage of doing this is that it enables me to describe the difference between Smith-love and a triadic variant of Smith-love wherein one person loves the plurality of herself and two others. In this variant, as in the case of Smith-love, both the subject and the object of the love relationship are a single entity (the object being a plurality in each case). But it is important to have a way to express the difference between them, and my linguistic policy will be to use "dyadic" and "triadic" in such a way as to track this this difference. In this terminology, Smith-love has two parties and its triadic variant has three parties (although in both cases the relation between lover and beloved plurality is two-place).

To motivate his theory (which he understands as a synthesis of positions defended by Frankfurt (2004) and Nozick (1989)), Smith writes: 
Many of the things lovers do ... bring distinctive benefits just when they are done by loving couples, e.g. having children, or seeing a film, or attending yoga classes. But even this is not the whole truth. Of especial interest are those activities, such as snuggling up, or holding hands, or going for walks, or chatting together about the day's events, or looking into each other's eyes, or simply rubbing along together (sharing the same space), which are, on the face of it, beneficial not because they serve some further end of either party, but because the parties accord non-instrumental value to them. (2OII: 77)

Again, noteworthy here is the claim of distinctiveness of the benefits that accrue to loving couples (in Smith's sense of exclusive dyads) through undertaking certain activities.

If indeed romantic love can only happen for exclusive dyads, and this is because of the distinctive beneficial possibilities offered by exclusive dyadicity, then Modal Monogamy is true. Thus the letter of Smith's account entails Modal Monogamy.

However, despite Smith's claim that there are distinctive benefits that accrue to loving couples pursuing these activities, there is in fact no obvious reason why these benefits couldn't accrue to (e.g.) loving triads doing the same things. Nothing on the list suggests that two-ness per se is particularly relevant.

Three people can raise a child, for example. There is no reason to doubt this once we set aside the empirically disproven assumption that a child can only be successfully raised by exactly one biological mother and exactly one biological father who are in an exclusive dyadic romantic relationship. (This assumption must give way to the evident fact that adoptive parenthood, single parenthood, samesex parenthood, blended families, child-rearing by older siblings, grandparents or other relatives, and many other configurations can all be successful ways to raise a child.) The possibility of having more than two parents, while long established by de facto practice, has also recently begun to be recognized with respect to legal parenthood; a child recently born in British Columbia has three legal parents listed on her birth certificate, for example. ${ }^{14}$ And given that child-rearing is extremely demanding work, there is reason to think that increasing the number of parents may at least sometimes help rather than hinder the project. This is, I take it, a rather widely-held view with respect to the difference between solo parenting and parenting as a couple. (It is an important question for Smith, though not one I can pursue in this paper, whether the "distinctive benefits" of parenting as a couple mean that single-parent families are in some "distinctive" way deficient.)

Similarly, three people can see a film, snuggle, and even stare at each other

I 4. http://www.cbc.ca/news/canada/british-columbia/della-wolf-is-b-c-s-1st-child-with-3-parents-on-birth-certificate- 1.2526584 
quite effectively. If there is supposed to be some reason why these activities would be somehow less distinctively beneficial were three people involved rather than two, the burden of proof is on Smith to provide that reason.

Absent such argument, the limitation to the dyadic case seems unmotivated, and Smith's account appears to exclude cases which, while they may be culturally non-standard (at the time and place at which Smith is writing), and even "inappropriate" according to Smith, appear nonetheless to be metaphysically possible. I take it that good metaphysics should not restrict what is possible to what is normal at a particular time and place, nor even to what is appropriate. ${ }^{\mathrm{I} 5}$

Moreover, although Smith's view as presented covers only exclusive dyadic love, it turns out to be quite amenable to adjustment to include at least the nondyadic cases. In the following, bold type is used to indicate where changes have been made:

Each lover participates, with the other(s), in doing things of the mentioned sorts out of Frankfurtian love: his love for the activities, which, in turn, is expressive of his love for the plurality of agents of them. The latter love has the four features Frankfurt lists, it is disinterested, rigidly focussed, identifying and involuntary. But it has, as its object, a plurality of people, oneself and one's partner(s).

The hypothesis accommodates Frankfurt's view almost completely. He is quite right about the nature of love, according to the hypothesis. It is just that he overlooks the possibility that love may have a plural object. In particular, he overlooks the possibility that each one of $n$ lovers may love, not just the other(s) but all of them, collectively. Such love, I hypothesise, is distinctive of romantic love, it finds expression in doing things, of the sort described, with one's beloved(s), things valued for themselves, simply because they are expressive of such love for a plurality.

The hypothesis also accommodates Nozick's account in the following way. Whilst he is right to say that lovers want to form and sustain a we, what he neglects to observe is that something distinctive of romantic love is that the desire in question is no mere desire; it is Frankfurtian loving concern, which is, unlike the desires to form wes had by business or creative partners, both a disinterested, and an involuntary one.

I 5. It is not particularly relevant here whether or not Smith himself uses the label "metaphysics" for his work; what matters for my purposes is the extent to which the view he defends includes metaphysical claims and/or has metaphysical consequences. The same goes for the work of Ruth Chang discussed in section 4 below. Thanks to Colin Klein for encouraging me to think about this point. 
I'm not here concerned about whether the adjusted thesis is true or not, but with how easy the adjustment is to make. The third paragraph requires no change at all, and the first two require only very minor and obvious tweaks.

This is not to say all the interesting work has been done by these tweaks. (There is more to be said about Smith's attempt at reference-fixing, for example.) But amending the actual account to include non-dyadic cases requires very little work. And amending for non-exclusive cases seems to require even less: just not setting out by taking for granted a culturally standard set of assumptions about what counts as a "couple" (or more generally, what love relationships are like) should suffice here. The letter of the account need not be any further altered once we are being careful about such assumptions, as it already seems to allow for multiple concurrent $n$-place love relationships.

In fact, without intending to, Smith offers assistance the theorist of love who does not restrict love to the dyadic case in an appendix to his paper ( $\mathbb{V}$ VIII). In this appendix Smith argues that even when a relation is paradigmatically dyadic, its two argument places can each be filled by either one thing or more than one thing. He says that "Loving is a textbook example of a non-symmetric dyadic relation", but that this is quite consistent with the object of love being a plurality (83).

Of course Smith is not here intending to defend the possibility of nonmonogamous love. Rather, he is trying to defuse a consequence of his own account of love, which holds that romantic love is borne by each of two parties towards the pair of them. To support his claim about how dyadic relations work, Smith (referencing Morton 1975) gives examples such as the following:

Fighting is dyadic. It has a gap for whomsoever fights and a gap for whomsoever is fought. But, as Morton noted, each gap may be filled by more than one thing. As he writes "... it can relate, say, four objects ('Adam and Bill fought ... Yuri and Zero').” (Smith 20I I: 85)

But just the same kind of argument could be used to defuse any concern to the effect that loving's being a "textbook case of a dyadic relation" means that all love relationships must be dyadic in the sense at issue in this paper.

It does not much matter for my purposes whether we follow Smith and maintain that the loving relation is dyadic but each argument place may be filled by multiple things, or instead hold that the loving relation is not dyadic but multigrade. (To the latter view it may or may not be appended that the word "loves" is syntactically dyadic although the loving relation is multigrade.) It strikes me that the simplest option, and the easiest way of accommodating all the (apparent) data points, would be to say the loving relation is multigrade. ${ }^{\mathrm{I}}$

I6. Among other advantages, treating the relation as multigrade could help make sense of the phenomenon of being in love in non-monogamous cases. On the envisaged model, for three people 
But there are other ways to navigate around these issues too. My point is that something along these lines will be required to accommodate the case of fighting mentioned by Smith (and many other structurally similar cases). And any of the options will allow for the possibility of non-dyadic love relationships in the sense at issue in this paper. Smith is right, of course, that introductory logic courses often teach students how to translate sentences like "Aeron loves Bai”. That doesn't mean that there is any metaphysical, semantic, or logical trouble lurking as soon as we progress to sentences like "Aeron, Bai and Cemal love each other".

\section{4. "The One"}

In her (20I3), Ruth Chang discusses the kinds of commitments that "are those typically made to people in relationships of love and friendship, and most paradigmatically in relationships of romantic love" $(76)$. The nature of these commitments, Chang argues, is importantly internal. With respect to romantic love, she says:

Hollywood gets the point. Jack is a wild, fun-loving, carefree bachelor who spends his free time drinking and road-tripping with his male buddies. $\mathrm{He}$ has serial one-night stands but can't seem to sustain a romantic relationship. Then he meets Jill, who seems different from every other woman he's met. They go ice skating in Rockefeller Center and engage in mildly witty repartee. But Jill has his number; she's not going to 'commit' to him until she sees that he 'commits' to her. What is it that Jill wants from Jack? Does she want Jack to make a promise to her - to love and to cherish her in just the way he might promise to take her to lunch or to pick up her dry cleaning? Both Jill and the audience know exactly what Jack needs to do: he needs to commit to her in the sense of interest - to do something all by himself, to resolve internally that she is 'the one'. This internal commitment

to be in love is for them all to stand in a three-place loving relation together, while the two-place loving relation can at most capture the fact that Aeron and Bai (that is, the two of them qua unit) love Cemal, etc. To the extent that one wants to distinguish the three of them being in love from the obtaining of these several two-place relationships, which I am inclined to think it would be useful to be able to do, treating loving as multigrade could help.

Another fascinating issue in this vicinity concerns whether there might be different issues that arise for (and different arguments concerning) the loving relation considered as one-one, one-many, many-one, and many-many. For example, in order for loving to be sometimes many-one or manymany, it must be that loving is sometimes a thing that pluralities do, as opposed to just something that is sometimes done to a plurality. It doesn't follow from the possibility of love sometimes being one-many that such a many-one situation is also possible. (Thanks to Rachael Briggs for helping me to think about this. I hope to address these and related questions about the workings of the loving relation in more detail in further work.) 
usually comes to Jack in a flash, and just in the nick of time before Jane is to board a plane to work with indigenous populations in the remote regions of the Amazon. The promise to love and to cherish comes later, at the closing wedding scene, when the credits roll and everyone is supposed to leave the theatre feeling romantically uplifted. (78)

I agree with Chang that this is the image of romantic love that many Hollywood movies depict. I am less convinced, however, that Hollywood fully "gets the point" as far as the nature of romantic commitment goes.

Chang is most concerned in this passage (and, more generally, in her paper) to press the claim that it is some internal resolution that is characteristic of committed romantic love. I have no quarrel with that claim. However, resolving that someone is "the one" is a matter of committing oneself to an exclusive and dyadic relationship. And given that Modal Monogamy is false, treating a commitment to exclusive dyadicity as constitutive of the distinctive romantic commitment means that Chang's account of the distinctive nature of romantic commitment is insufficiently general to capture all the cases.

It might be imagined that a more charitable reading of Chang is available on which she does not really intend commitment to somebody as "the one" is distinctive of the romantic commitment in all cases. However, Chang's reference to "the one" isn't a one-off that occurs only in the quoted passage; she returns to the idea of committing to a partner as "the one" throughout her discussions of romantic commitment, and this phrase seems to be intended to convey the core of her take on how to conceive of the distinctive commitment of romantic love. We are not given any substantive handle on what the distinctive commitment might amount to when it is not a commitment to "the one".

Chang intends us to be able to pick up on the details of what she intends by the phrase "the one", assuming that the cultural background of her intended readership will fill in the details as to what committing to somebody as "the one" amounts to. (It is not, for example, supposed to include resolving that "the one" is the only person you will have a conversation with ever again. But it is supposed to include resolving that "the one" is the only person you will have sex with, at least for the duration of this romantic relationship and potentially for ever.) I think it is a very reasonable assumption that social context will do this filling-in work if allowed to do so. There are dominant paradigms of romantic love, embedded in the cultural background against which Chang is writing, that will readily fill in many details of what romantic love is supposed to look like. These details will centrally include exclusivity and dyadicity. The phrase "the one" efficiently conveys the importance of both of these central features.

However, I would not in general advise philosophers to rely too heavily on culturally dominant paradigms of love to do heavy lifting in philosophical theo- 
ries. This seems particularly important when we have prior reason to think those paradigms are not representative of a very wide range of cases of the phenomenon they concern. And we do not have to look very far to appreciate that this is the case with romantic love: the prevalent stereotype of romantic love in the cultural context to which Chang's mention of Hollywood averts includes many features that are less than maximally representative or inclusive, including perhaps most obviously heteroromanticism, assumptions about how romantic behaviours relate to gender, ${ }^{17}$ and assumptions about how love relates to sex and marriage. ${ }^{18}$

Chang may well be right that there is a characteristic internal commitment that makes committed romantic relationships what they are, and this strikes me as an important point if true. But whatever that commitment is, there is more work to be done by way of locating it than can we can achieve by relying on Hollywood. As Haslanger says, "[p]hilosophical analysis has a potential for unmasking ideology, not simply articulating it" (2006: I I 7). I think the topic of romantic love is a particularly fertile ground for the exercise of this potential.

By contrast with my discussion of Smith's view in section 3 above, where it seemed that the needed tweaks to Smith's account could be readily found, it is less obvious to me what an immediate fix might look like in the case of Chang's proposal. It might be imagined that the relevant commitment can sometimes consist in resolving that someone is "a one", or that some people are "the ones", instead of always being a matter of resolving that someone is "the one". ${ }^{19}$

However, one difficulty with this is that "the one" is being employed as a convenient shorthand label that efficiently brings to mind a number of features typically associated with romantic love. Change that label to "a one" or "the ones", and it is not at all clear which bits of the original feature-bundle are supposed to be preserved. There are many different forms a non-monogamous relationship can take, and these will preserve different things from the original feature-bundle. For example, some polyamorous triads preserve the romantic exclusivity typical of a "the one" relationship but not the dyadicity; some $V$ relationship structures preserve the dyadicity but not the exclusivity; some non-monogamous people consider one of their partners their "primary" partner, and on that basis might decide to preserve several of the features typical of a "the one" relationship in their primary relationship (such as sharing living arrangements and finances only with the primary partner, prioritising the relationship with the primary partner over other

I7. Indeed, both heteroromanticism and gender-stereotypical romantic behaviours are also noticeably embedded in the Hollywood-esque vignette presented by Chang.

I8. Like discussions in the philosophy of love, some aspects of the range of stereotypical presentations are gradually changing over time. For example, a Hollywood audience is more likely now than twenty years ago to accept Jack and John as romantic leads. But that doesn't mean that heteroromanticism has entirely detached itself from the stereotype. And it surely doesn't mean that Hollywood presents a broad enough range of stories to do heavily lifting in the philosophy of love.

I9. Thanks to my anonymous referees for suggesting I discuss this kind of strategy. 
relationships, and so on), but then might have a secondary love relationship which has very few of these features. Others think of their non-monogamous relationships as non-hierarchical, and may be in multiple love relationships none of which looks at all like a typical "the one" relationship.

So, while I think I have a fairly good sense of what resolving that Jill is "the one" in the Hollywood sense is supposed to amount to, I find I can think of many different things that resolving that someone is "a one" or "one of the ones" might amount to, and I don't know which if any of these would be the sort of thing that ought to satisfy the Chang proposal when revised in the envisaged way.

For that reason, the envisaged fix is not going to be a quick one. I do, however, think the pursuit of a revision along these lines would be a make for a very interesting project. $^{20}$

\section{Intuitions and Ideology in Advanced Metaphysics}

Let me now return to address the claim, postponed from section 2, that Modal Monogamy is intuitive, true by definition, a conceptual truth, or something like that.

As mentioned above, Soble is one of those who includes dyadic exclusivity as a necessary feature in a conceptual analysis of romantic love. He spells out his views on this matter even more thoroughly in Soble (unpublished manuscript), where he says:

I believe that exclusivity has to be an essential part of romantic love. Intuitively, I cannot conceive of romantic love that is anything but exclusive. It seems patently obvious that romantic love requires exclusivity - two people who are exclusive and belong only to each other.

My main reason for thinking that exclusivity is a necessary feature of romantic love is that it just makes sense. (2)

20. Such a project might helpfully draw on the work of Elizabeth Brake (20I2) concerning the nature of romantic commitment. Brake writes: "The term commitment is ambiguous between an internal psychological disposition that manifests in action ... and an act of voluntarily undertaking responsibility" (44), and commitment in the former sense may be a good candidate for being the sort of thing Chang has in mind in her (2013). For Brake, as for Chang, a commitment (in the relevant sense) to a lover is an internal matter, independent of external acts like promising or making wedding vows. Brake adds that a commitment by itself does not by itself create any moral obligations, but consists in a kind of disposition (and she offers a substantive theory about what kind of disposition it is). Brake is also explicit that, in her view, " $[\mathrm{t}]$ he structure of prudent love commitments is not defined by the nature of romantic love, but depends on the preferences and propensities of each individual good" (2OI2: 55-6). This flexibility enables Brake's account of romantic commitment to accommodate both non-dyadic and non-exclusive cases. I am grateful to an anonymous referee for pointing out to me the relevance of these aspects of Brake's work for this project.

Ergo • vol. 2, no. 8 • 2015 
This is not very dialectically compelling; it reads as more of an internal status report than an argument. But evidently, for Soble at least, the intuitiveness of monogamy is a big deal. Can such intuitions be explained in a way that makes room for the possibility of non-monogamous love? I believe so.

I start with a very general cautionary note. Unreflective claims about what is "intuitive" run the risk of sliding between what strikes the speaker as commonsensical on the one hand, and what is a matter of definition or a conceptual truth on the other. Philosophers use "intuition"-talk for both of these things, but they are very different. (I develop this point in more detail in Jenkins 20I4.)

Zooming in a little, it is noteworthy we are here in the realm of what I call "advanced metaphysics": dealing with matters that go far beyond what is metaphysically fundamental or basic. Advanced social metaphysics in particular is an area where any flat-footed application of intuitive methodology is fraught with the risk of sliding between what is "commonsensical" and what is a matter of definition.

The Hollywood-style paradigm prominently and unquestioningly includes features like monogamy, heteroromanticism, a slew of gendered behavioural norms, the assumption that romantic relationships are sexual, and a lot more. And it is so deeply culturally ingrained that one would expect exceptions to it to strike people as "counterintuitive" on first encounter. They certainly aren't going to seem "normal" or "commonsensical". But when a paradigm is as thoroughly culturally embedded as this one is, particular vigilance is needed to avoid the risk of mistaking its contours for those of a bona fide definition or conceptual analysis. The central features of such an ingrained paradigm are bound to feel "intuitive" and "correct" whether or not those features correspond to matters of definition or conceptual truth.

In addition to having good general reasons to be cautious about "intuition" when engaging topics where deeply embedded dominant cultural paradigms are operative, we have specific reason to be cautious about this in the case of romantic love. For, even setting monogamy aside, it is already evident that there are many features of the dominant paradigm that cannot be appropriately taken as limning either what is metaphysically possible when it comes to love or the contours of our concept of love. Perhaps most obviously, these include heteroromanticism and romantic gender-stereotyping. (In fact the Hollywood-style love stereotype fails on so many counts to limn the necessary conditions on love that, if nothing else, this sheer weight of numbers could make us suspicious as to whether the monogamy feature of that stereotype marks any such necessary condition.)

As if this weren't already enough, ${ }^{2 \mathrm{I}}$ we should also be alert to the possibility of ideological interference with the relevant "intuitions". In section I, I floated the idea that mentioned Moral Monogamy may sometimes be tacitly motivating, or

2I. It is.

Ergo • vol. 2, no. 8 • 2015 
confused with, Modal Monogamy. I want to finish up by adding a little more detail to that suggestion.

The Hollywood-style stereotype of love does not operate independently of attributions of value. It both reflects and reinforces social norms about what love is supposed to be like, what kinds of love are worth treating as serious, and so on. In this connection, therefore, it is helpful to draw on the insights of social constructionists such as Sally Haslanger concerning philosophical reliance on intuitions and conceptual examination in areas where ideological interference is a risk factor. Haslanger puts the point this way:

It is an important part of the social constructionist picture that, to put it simply, our meanings are not transparent to us: often ideology interferes with an understanding of the true workings of our conceptual framework and our language. More specifically, ideology (among other things) interferes with our understanding of our classificatory practices, suggesting to us that we are finding in nature divisions that we have played an important role in creating. (2006: 92 )

It is, I take it, rather plausible that romantic love is (at least in part) a socially constructed kind, and even more plausible that our ordinary understanding and classificatory practices around love are ideology-laden. I therefore contend that Haslanger's claims about the non-transparency of our conceptual framework are very plausible in application to romantic love.

If that is right, this Haslangerian thought can be applied to resist claims to the effect that (e.g.) a romantic love relationship is intuitively, or by definition, a relationship that only ever obtains among exclusive dyads. It can equally be applied to question claims to the effect that romantic love so conceived is a natural phenomenon (in the sense that what cases of romantic love have in common is not in any way created by our decisions about how to classify but by a joint in nature). The social constructionist can argue in response to both kinds of claim that ideology is interfering with our understanding of the category of romantic love, rendering us liable to mistakes both about the contours of our concept and the role of social classificatory practices in creating and sustaining those contours.

Given the strength of the arguments against Modal Monogamy, then, together with the relative ease with which even very robust intuitions in its favour can be shown to be suspect on multiple counts, it is my contention that monogamy is best understood as a feature of a dominant paradigm of romantic love, and should not be inflated into a metaphysically necessary condition. 


\section{Acknowledgements}

I am grateful to Rachael Briggs, Susan Fowler, Ray Hsu, Jonathan Jenkins Ichikawa, Colin Klein, Kris McDaniel, Paul Prescott, Fiona Woollard, Audrey Yap, my audience at the GRSelona II conference, and anonymous Ergo reviewers for helpful comments and feedback. This paper was written under the aegis of The Metaphysics of Love Project, funded by a Hampton Research Grant from the University of British Columbia.

\section{References}

Brake, Elizabeth (2012). Minimizing Marriage. Oxford University Press.

Caraway, Carol (1987). Romantic Love: A Patchwork. Philosophy and Theology 2(I), 76-96. Reprinted in Alan Soble (Ed.), Sex, Love and Friendship: Studies of the Society for the Philosophy of Sex and Love (403-20). Rodopi. http://dx.doi.org/I0.5840/ philtheoli9872I2I

Chang, Ruth (2013). Commitments, Reasons, and the Will. In Russ Shafer-Landau (Ed.), Oxford Studies in Metaethics, 8, (74-II3). http://dx.doi.org/I0.I093/acprof:o so/9780199678044.003.0004

Frankfurt, Harry (2004). The Reasons of Love. Princeton University Press.

Halwani, Raja (2010). Philosophy of Love, Sex and Marriage: An Introduction. Routledge.

Haslanger, Sally (2006). What Good Are Our Intuitions? Aristotelian Society Supplementary Volume, 80, 89-I I 8. http://dx.doi.org/IO.I I I I/j.I 467-8349.2006.00I39.x

Illouz, Eva (2012). Why Love Hurts. Polity Press.

Jenkins, Carrie Ichikawa (20I4). 'Intuition', Intuition, Concepts and the A Priori. In A. Booth and D. Rowbottom (Eds.), Intuitions (9 I-I I 8). Oxford University Press. http:// dx.doi.org/I0.1093/acprof:0so/9780199609192.003.0006

Jollimore, Troy (20II). Love's Vision. Princeton University Press. http://dx.doi. org/IO.I 5 I 5/978 I 400838677

Kisolo-Ssonko, Joseph (20I 2). Love, Plural Subjects \& Normative Constraint. In Phenomenology and Mind, 3, 54-64.

Liao, S. Matthew (2006). The Idea of a Duty to Love. Journal of Value Inquiry, 40(I), I-22. http://dx.doi.org/I0.I007/s I0790-007-90I3-8

Morton, Adam (I975). Complex Individuals and Multigrade Relations. Nô̂s, 9(3), 309I 8. http://dx.doi.org/I0.2307/2214634

Nozick, Robert (1989). Love's Bond. In Robert Nozick, The Examined Life: Philosophical Meditations. 68-86. Simon \& Schuster.

Smith, Thomas (20I I). Romantic Love. Essays in Philosophy, I2(I), 68-92.

Soble, Alan (I987). The Unity of Romantic Love. In Philosophy and Theology, I(4), 37497. Reprinted in Alan Soble (Ed.), Sex, Love and Friendship: Studies of the Society for the Philosophy of Sex and Love (385-402). Rodopi. http://dx.doi.org/I0.5840/ philtheolı987I4I3 
Soble, Alan (unpublished manuscript) What Is Romantic Love? Retrieved from http://forums.catholic.com/attachment.php? attachmentid=9934\&d=1300009573 Accessed March I3, 20II.

Solomon, Robert (I988.) About Love: Reinventing Romance for Our Times. Simon \& Schuster.

Weaver, Bryan, and Fiona Woollard (2008.) Marriage and the Norm of Monogamy. The Monist, 9I(3-4), 506-22. http://dx.doi.org/IO.5840/monist20089I3/428 